\title{
Prevalence and risk factors of ticks infesting cattle reared on the main campus of Haramaya University, Eastern Ethiopia
}

\author{
Adem Abdella, Yimer Muktar and Adem Hiko* \\ College of Veterinary Medicine, Haramaya University, P.O. Box. 138 Dire Dawa, Ethiopia \\ *Corresponding Author: E. mail: adex.2010ph@gmail.com \\ https: / /dx.doi.org/10.4314/evj.v21i1.2
}

\begin{abstract}
Tick infestation is a major problem constraining animal production and productivity in Ethiopia showing the need for tackling the situation. A crosssectional study was carried out to determine tick prevalence and associated risk factors among cattle reared on dairy, beef and free-range grazing farms of Haramaya University from November 2014 to April 2015. A total of 519 animals were randomly selected. Ticks were collected and identified under stereomicroscopic examination. A total of $384(73.9 \%)$ animals were positive for tick infestation which was higher on both beef (79.2\%) and dairy (82.3\%) than on free-range grazing $(32.4 \%)$ cattle with $\mathrm{OR}=8(95 \% \mathrm{CI} 4.2-16.9)$ and $\mathrm{OR}=$ 9 (95\% CI 5.0-18.8) in beef and dairy animals, respectively. Infestation was significantly lower on Borana breed (20\%; $95 \%$ OR CI 0.5-1.99) than on others. Difference in infestation between sexes and among the age groups of animals were not observed $(p>0.05)$. Of positive cattle, $52.9 \%, 12.8 \%, 7.0 \%$ and $27.3 \%$ were infested with single, two, three and four genera of ticks, respectively. In positive animals, subgenus Boophilus (51.0\%), Amblyomma (58.3\%), Hyalomma (48.2\%) and Rhipicephalus (53.1\%) tick genera were observed. Multiple tick genera infestation were more frequent in cattle managed under both beef (34.7 to $62.9 \%$ ) and dairy (22.2 to $55.1 \%$ ) farm types than that of free-range (4.4 to $14.8 \%$ ) farm types. All the currently encountered tick genera infested $48.5 \%, 46.8 \%$ and $4.8 \%$ of beef, dairy and free range grazing cattle farms, respectively. The result showed all animals are found in endemic environment for tick infestation and thus the burden might cause economic loses mainly by reducing milk and meat yields, body weight gain, skin and hides quality, and risk of tick-borne diseases. Therefore, tick infestation in the study farms warrants strategic tick control approaches.
\end{abstract}


Keywords: Beef farm; Dairy farm; Free-range grazing; Infestation; Tick genera

\section{Introduction}

Tick infestation and tick-borne diseases (TBDs) are the major problems in livestock production in Sub-Saharan Africa (Mattioli et al., 2000; Jongejan and Uilenberg, 2004). Tick-borne diseases, namely, East Coast Fever, anaplasmosis, babesiosis and cowdriosis have been reported to affect the optimal livestock productivity in East African region (McCosker et al., 1993). Apart from acting as vectors for TBDs, ticks have been recognized as important ectoparasites of livestock by sucking blood, causing local necrosis which results in low quality hides (Jongejan and Uilenberg, 2004), secondary bacterial infections (Ambrose et al., 1999), lowering productivity in terms of weight gain (Pegram and Oosterwijk, 1990) and milk yield (Sajid et al., 2007), increasing susceptibility to the other diseases (De Castro, 1997), dermatosis, toxicosis and paralysis (Solomon Gebre and Kaaya, 1998). Based on the number of hosts required to complete their development during their life cycle, ticks can be classified as one-host, two-host and three-host ticks (Walker et al., 2003). Due to medical and veterinary importance of ticks, their control and the transmission of tickborne diseases remain a challenge for the cattle industry in tropical and subtropical areas of the world (Lodos et al., 2000). Tackling ticks is a priority for many countries in tropical and subtropical regions (Lodos et al., 2000) including Ethiopia (Solomon Gebre and Kaaya, 1998; Sileshi Mekonnen et al., 2001; Feyissa Regassa, 2001). In Ethiopia, ticks incur the economic loss when they infest cattle. Several previous studies were made on tick prevalence, body distribution, number, male to female ratio (Solomon Gebre and Kaaya, 1998; Mekonnen Sileshi et al., 2001; Feyissa Regassa, 2001; Belew Tiki and Mekonnen Addis, 2011, Tadesse Birhanu and Sultan Abdella, 2014) on cattle in different parts of Ethiopia. Although ticks cause huge economic loss of significance in the livestock industry in Ethiopia, not much research work has been done to elucidate the extent of the problem in the present study area. Therefore, this study was conducted to determine tick prevalence and degrees of infestation as well as associated risk factors in three cattle farming systems of Haramaya University in Ethiopia. 


\section{Materials and Methods}

\section{Study area}

The study was undertaken from November 2014 to April 2015 on the main campus of Haramaya University, which is located in the East Hararighe Zone of Oromia Regional State, Ethiopia, at the distance of about $500 \mathrm{~km}$ east of Addis Ababa, the capital city of Ethiopia. The altitude of study area is about $2047 \mathrm{~m}$ above sea level and located at $41^{0} 59^{\prime} 58^{\prime \prime}$ latitude and $09^{\circ} 10^{\prime} 24^{\prime \prime}$ longitudes. The area has native grasses and legumes interspersed vegetation with open Acacia shrub land and $18^{\circ} \mathrm{C}$ mean annual temperature and $65 \%$ relative humidity and receives $900 \mathrm{~mm}$ annual rainfall with a bimodal distribution pattern, peaking in mid-April and mid-August. There are four seasons, as a short rainy season (mid-March to mid-May), a short dry season (end of May to end of June), a long wet season (early July to mid-October) and long dry season (end of October to end of February). Main pasture production is expected after the short rain season, continuing until the end of the long wet season (NMSA, 2013).

\section{Study animals and farm description}

The animals selected for the study were drawn from different production systems: dairy, beef and free grazing production systems. The dairy farm consisted of Holstein Friesian and Jersey exotic breeds with few pasture grazing period. Preventive veterinary practices like use of anthelmintics, vaccination, manual removal and other biosecurity were periodically applied (Adem Hiko and Anteneh Wondimu, 2011). Beef farm animals are mainly the Hararighe highland local breed purchased from different districts of East Hararighe Zone, of Oromia Regional State. The animals are kept for three or more months under semi-extensive farming system with frequent grazing. On the other hand, the free-range grazing production system is of the Borana local breed cattle used mainly for research purpose. They are totally kept under free range pasture grazing condition.

\section{Study design and sample size determination}

A cross-sectional study was carried out on the selected cattle farm type. The required sample size for the study was determined according to formula given by Thrusfield (2007) at 50\% expected prevalence, $5 \%$ desired precision and $95 \%$ confidence interval. The computed sample size was 384 , but the number 
was increased to 519 animals. These animals were sampled using systematic random sampling techniques by taking into account the variation of age, sex, breeds and body condition of animals of the 3 breeds of cattle. Age of the animals were determined as young ( $<1$ year), adult (1-3 years) and old ( $>3$ years) (Nicholson and Butterworth, 1996). The body condition scores were classified as good, medium and poor were based on criteria set by Nicholson and Butterworth (1996).

\section{Tick collection and laboratory examination}

The whole body part of each study animal was examined for the presences of ticks. From positive animals, ticks were collected into universal bottles by considering the body regions of the animal. The collected ticks were preserved in 70\% ethyl alcohol and transported to Parasitology Diagnostic Laboratory, College of Veterinary Medicine, Haramaya University. Identification and classification into respective genera was made according to Walker et al. (2003) guidelines using gross and stereomicroscopic examination.

\section{Data analysis}

The collected data from the field were entered into excel sheet and analyzed by using SPSS version 20. Microsoft excel spread sheet. The data were analyzed by using Statistical Package for Social Students (SPSS) version 21 and WinPepi 11.35 soft wares. Descriptive statistics was used to determine the tick infestation and assess any association between the tick infestations with host risk factors (sex, age, breed and body condition score). In all the analyses, confidence level was held at $95 \%$ and $\mathrm{P}<0.05$ was set for significance.

\section{Results}

Overall 73.9\% of examined cattle were positive for tick infestations (Table 1). Tick prevalence in free-range grazing farm (32.4\%) was significantly lower than in both beef farm (79.2\%; OR $=7.9 ; 95 \%$ OR CI $4.2-16.9)$ and dairy farming (82.3\%; OR $=9.6$; 95\% OR CI 5.0-18.8). Significantly lower $(\mathrm{p}<0.05)$ on Borana breed (20\%; 95\% OR CI 0.5-1.99) than others. But differences in infestation between sex gropes $(p>0.05)$ and among age groups of animals were not observed ( $p>0.05)$. 
Table 1. Overall tick prevalence in study cattle farming systems based on the considered risk factors.

\begin{tabular}{|c|c|c|c|c|c|c|}
\hline \multicolumn{2}{|c|}{ Risk factors } & \multirow{2}{*}{$\begin{array}{l}\text { No. } \\
\text { Examined } \\
71\end{array}$} & \multirow{2}{*}{$\begin{array}{l}\begin{array}{l}\text { No. (\%) } \\
\text { Positive }\end{array} \\
23(32.4)\end{array}$} & \multirow{2}{*}{$\begin{array}{c}\text { OR* } \\
1\end{array}$} & \multirow{2}{*}{$\begin{array}{l}\begin{array}{l}\text { 95\% OR } \\
\text { CI }\end{array} \\
0.6-1.6\end{array}$} & \multirow{2}{*}{$\begin{array}{r}P \text {-value } \\
0.00\end{array}$} \\
\hline Farm type & Free grazing farming & & & & & \\
\hline & Beef farming & 245 & $194(79.2)$ & 7.9 & $4.2-16.9$ & \\
\hline & Dairy farming & 203 & $167(82.3)$ & 9.6 & $5.0-18.8$ & \\
\hline \multirow[t]{4}{*}{ Breed } & Borana & 65 & $13(20.0)$ & 1 & $0.5-1.99$ & 0.00 \\
\hline & Holstein Friesian & 178 & $145(81.5)$ & 17.6 & $8.2-38.6$ & \\
\hline & Hararighe $\mathrm{H}^{*}$ & 247 & $202(81.8)$ & 17.9 & $8.6-38.6$ & \\
\hline & Jersey & 29 & $24(82.8)$ & 19.2 & $5.5-74.1$ & \\
\hline \multirow[t]{2}{*}{ Sex } & Female & 244 & $167(68.4)$ & 1 & $0.9-1.13$ & 0.174 \\
\hline & Male & 275 & $217(78.9)$ & 1.7 & $1.14-2.6$ & \\
\hline \multirow[t]{3}{*}{ Age } & Adult & 216 & $145(67.1)$ & 1 & $0.6-1.52$ & 0.06 \\
\hline & Young & 79 & $54(68.4)$ & 1.1 & $0.59-1.9$ & \\
\hline & Old & 224 & $185(82.6)$ & 2.3 & $1.45-3.7$ & \\
\hline \multirow{3}{*}{$\begin{array}{l}\text { Body } \\
\text { condition }\end{array}$} & Good & 231 & $134(58.0)$ & 1 & $0.68-1.47$ & 0.00 \\
\hline & Medium & 224 & $187(83.5)$ & 3.6 & $2.3-5.8$ & \\
\hline & Poor & 64 & $63(98.4)$ & 45 & 7.5- 184 & \\
\hline Total & & 519 & 384 (73.9) & & & \\
\hline
\end{tabular}

Four tick genera, consisting Subgenus Boophilus, Amblyomma, Hyalomma and Rhipicephalus were observed respectively on $51.0 \%, 58.3 \%, 48.2 \%$ and $53.1 \%$ infested animals (Table 2). Infestation percentage by these tick genera was variable in degrees but observed in all farm types, breed, sex, age and body condition of animals.

As shown in Fig.1, single to multiple of three tick genera and one subgenus infestation were frequent in cattle managed under both beef (34.7-62.9\%) and dairy (22.2-55.1\%) farming stems than that of free-range farm (4.4-14.8\%). 
Adem Abdella et al.,

Table 2. Prevalence of tick genera in study cattle farming systems based on the considered risk factors

\begin{tabular}{|c|c|c|c|c|c|c|}
\hline \multirow{2}{*}{\multicolumn{2}{|c|}{ Risk factors of }} & \multirow{2}{*}{$\begin{array}{l}\text { No. of } \\
\text { positive } \\
\text { animal }\end{array}$} & \multicolumn{4}{|c|}{ No. (\%) of positive animal for tick genus } \\
\hline & & & $\begin{array}{l}\text { Subgenus } \\
\text { Boophilus }\end{array}$ & Amblyomma & Hyalomma & Rhipicephalus \\
\hline \multirow{3}{*}{$\begin{array}{l}\text { Farming } \\
\text { system }\end{array}$} & Beef farm & 194 & $91(46.9)$ & $116(54.8)$ & $91(46.9)$ & $103(53.9)$ \\
\hline & Dairy farm & 167 & $93(55.7)$ & $91(54.5)$ & $83(49.7)$ & $89(53.3)$ \\
\hline & $\begin{array}{l}\text { Free grazing } \\
\text { farm }\end{array}$ & 23 & $12(52.2)$ & $17(73.9)$ & $11(47.8)$ & $12(52.2)$ \\
\hline \multirow[t]{4}{*}{ Breed } & Borana & 13 & $7(53.9)$ & $7(53.9)$ & $5(38.5)$ & $9(69.2)$ \\
\hline & $\begin{array}{l}\text { Holstein } \\
\text { Friesian }\end{array}$ & 145 & $86(59.5)$ & $80(55.2)$ & $71(48.9)$ & $74(51.0)$ \\
\hline & $\begin{array}{l}\text { Hararighe } \\
\text { Highland }\end{array}$ & 202 & $94(46.5)$ & $126(62.4)$ & $95(47.0)$ & $106(52.5)$ \\
\hline & Jersey & 24 & $9(37.5)$ & $11(45.8)$ & $14(58.3)$ & $15(62.5)$ \\
\hline \multirow[t]{2}{*}{ Sex } & Female & 167 & $95(56.9)$ & $95(56.9)$ & $88(52.7)$ & $88(52.7)$ \\
\hline & Male & 217 & $101(46.5)$ & $129(59.5)$ & $97(44.7)$ & $116(53.5)$ \\
\hline \multirow[t]{3}{*}{ Age } & Adult & 145 & 71 (48.9) & $89(61.4)$ & $74(51.0)$ & $83(57.2)$ \\
\hline & Young & 54 & $28(51.9)$ & $25(46.3)$ & $22(40.7)$ & $19(35.2)$ \\
\hline & Old & 185 & $97(52.9)$ & $110(59.5)$ & $89(48.1)$ & $102(55.1)$ \\
\hline \multirow{3}{*}{$\begin{array}{l}\text { Body } \\
\text { condition }\end{array}$} & Good & 134 & $72(53.7)$ & $76(56.7)$ & $62(46.3)$ & $75(55.9)$ \\
\hline & Medium & 187 & $99(52.9)$ & $111(59.4)$ & $96(51.3)$ & $92(49.2)$ \\
\hline & Poor & 63 & $25(39.7)$ & $37(58.7)$ & $27(42.9)$ & 37 (58.9) \\
\hline Total & & 384 & $196(51.0)$ & $224(58.3)$ & $185(48.2)$ & $204(53.1)$ \\
\hline
\end{tabular}

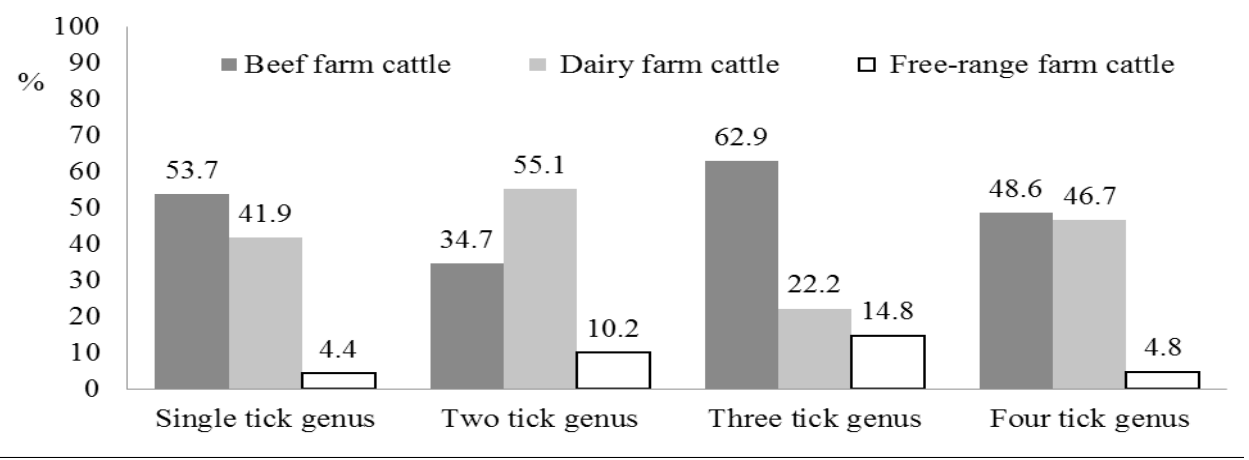

Figure 1. Single to multiple tick genera on cattle in the study farming systems 
For all genera combination, highest infestation was observed in beef farm followed by dairy than the free-range type (Table 3). Beef farm (48.5\%), dairy farm $(46.78 \%)$ and free range razing farm $(4.8 \%)$ tick positive cattle were infested by four tick genera (Subgenus Boophilus, Amblyomma, Hyalomma, and Rhipicephalus).

Table 3. Multiple tick genera from infested cattle by the cattle farm type

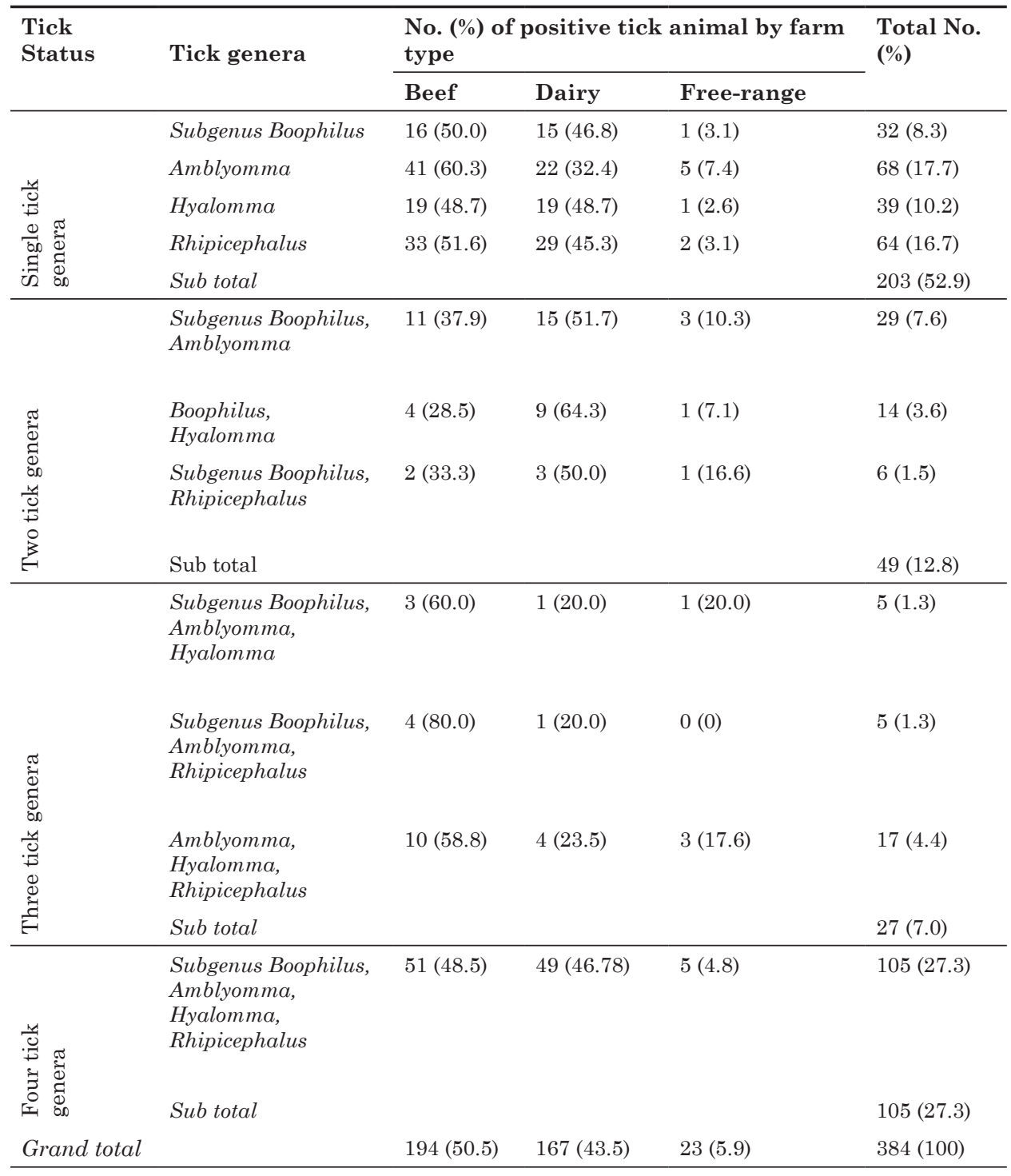




\section{Discussion}

Three hundred eighty-four (73.9\%) of examined cattle were found to be infested with one or more tick genera, showing high chance of tick occurrence in the studied farms. It was higher than the $25.64 \%$ previous reports of Belew Tiki and Mekonnen Addis, (2011) in Holeta, Ethiopia. Tick prevalence in the studied dairy farm (82.3\%) and beef farms (79.2\%) were significantly higher than in free-range grazing farms (32.4\%). This finding is consistent with the results reported of Pawlos Wasihun and Derese Doda (2013) in Humbo district, which was $61 \%$. However, the result of this study contrast the previous report of Belew Tiki and Mekonnen Addis (2011) who reported tick infestation of $45.4 \%$ in cattle kept under extensive production and $10.06 \%$ in those under semi-intensive farms. It was hypothesized that regular livestock management can be reduced tick infestation in semi intensive animal while movement in extensive farming exposes cattle to tick infestation (Pawlos Wasihun and Derese Doda, 2013; Belew Tiki and Mekonnen Addis, 2011). However, the present study dairy animals were kept under few grazing period after rainy seasons (Adem Hiko and Anteneh Wondimu, 2011) which might exposed endemic tick population within the farm and the surrounding area.

With regard to beef animals, relatively higher tick prevalence situation could be associated with the collection of already infested animal from different part of east Hararighie like Kersa, Chalenko, Kobo, Haramaya and others districts and kept without treatment until slaughter. This could due to distribution of tick population in various agroecology and infesting the livestock in the location. Mekonnen Sileshi (1996) has also reported the risk and distribution of various tick genera in cattle under various agroecology of Ethiopia.

The differences among breeds with low (20.0\%) in Borana breed cattle than the 81.5\% in Holstein Friesian, the $82.8 \%$ in Jersey and the $81.8 \%$ in Hararighe highland were contradictory with reports of Belew Tiki and Mekonnen Addis (2011) who reported the highest prevalence in local breed (44.96\%) than in both cross $(15.83 \%)$ and Jersey (8.50\%) breeds. The differences could be associated with the risk and differences in the farm management systems, prevalence of tick population in confined farm (Furlong et al., 2007). The majority of Borana breeds are free grazing which averted the risk of drug resistant tick (Kagaruki, 1991) in cases of the present study farm. The higher tick prevalence in those of Hararighe Highland breed might be associated with purchase of already 
infested beef cattle and kept still untreated, in the campus. These animals may also act as sources of various tick genera and species for the dairy and free grazing cattle farms as well as for sheep and goat in the respective farms.

The low tick prevalence $(58.0 \%)$ in those with good body conditions than in medium (83.5\%) and poor (98.4\%) body condition animals were similar to the reports of Getachew Alemu et al. (2014) on cattle in Northwest Ethiopia. The higher prevalence of ticks in the poor body condition scores than other counter parts could be due to the less resistance behavior of weak animals to ticks infestation and the condition was aggravated by significant effects of tick on animal performance.

This study revealed similar tick infestation in females (68.4\%) and males (78.9\%) animals which might be due to equal exposure of both sex groups of animal. Present finding is similar with the $63.4 \%$ in males and $60.9 \%$ in females reports of Musa et al. (2014) in Northern Nigeria. Again similar tick infestation among adult (67.1\%), young (68.4\%) and older (82.6\%) cattle were observed in this study which could be due to equal exposure of all studied animals regardless of age and sex under respective farming systems. But, tick infestation in younger animals had a significantly higher (85.4\%) than adult (55.8\%) and older animals (35.0\%) (Musa et al., 2014). The difference might be due to variation in their immunity level against tick in cattle of Ethiopia and Nigeria.

Subgenus Boophilus, Amblyomma, Hyalomma and Rhipicephalus were important genera of ticks encountered with a total prevalence of 51.0, 58.3, 48.2 and $53.1 \%$ respectively. Similar genera of ticks were reports in and around Asella town by Tessema and Gashaw (2010) and in Fitche Selale, North Shewa by Tadesse Birhanu and Sultan Abdella (2014) indicating the widely distributions of these tick genera in different agroecology and geographic areas Ethiopia. The current finding showed genera of subgenus Boophilus (51.0\%) in infested cattle in the study area and found higher than the $18.1 \%$ in and around Holeta Town (Belew Tiki and Mekonnen Addis, 2011), 15.4\% in and around Asella town (Tessema and Gashaw, 2010), in Rift Valley region of Ethiopia (Solomon Gebre and Kaaya, 1998), 23.5\% in Fiche (Tadesse Birhanu and Sultan Abdella, 2014). Morel (1980) stated that subgenus B. decolaratus is often collected in Ethiopia and abundant anywhere. But, the higher report from the current 
finding could be associated with the wetter highlands and sub-highlands environment of Haramaya district (NMSA, 2013).

The prevalence of Amblyomma (58.3\%) was comparable with $60.1 \%$ in and around Asella town (Tamiru Tessema and Abebaw Gashaw, 2010), but higher than the 39.1\% from Fiche by Tadesse Birhanu and Sultan Abdella (2014), 45\% in and around Assosa town (Bossena Fantahun and Abdu Mohamed, 2012) all from Ethiopia. Hyalomma (48.2\%) infested cattle was higher than the $12.4 \%$ (Tadesse Birhanu and Sultan Abdella, 2014) in Fiche and 2.5\% (Tessema and Gashaw, 2010) in and around Asella town. This could be due to differences in agroecology, animal management and Hyalomma tick burden in various area of the country. Rhipicephalus (53.1\%) was higher than the $22 \%$ (Tessema and Gashaw, 2010), 25.0\% (Tadesse Birhanu and Sultan Abdella, 2014). Moreover, the present finding of Rhipicephalus was higher than 31.4\% reports of Kassa and Yalew in 2012 from Haramaya district showing increased prevalence of this genus in the area either due to absence of animal treatment or change in whether condition.

The observation of $52.9 \%, 12.8 \%, 7.0 \%$ and $27.3 \%$ single, two, three and four tick genera combinations infested animals with diversified tick genera in Haramaya University main campus cattle farms, and possible co-existence of different tick genera both on infested animals and in geographic area with various distribution. Similarly Hezron et al. (2012), Lynen et al. (2008) and Ogden et al. (2005) indicated co-existence of different tick genera between the geographic distributions of one another. This could be due to presence of suitable shrub land, temperature, relative humidity, and bimodal rainfall distribution in the studied area (NMSA, 2013) which might be favor the survival and multiplication different tick genera in the presence cattle in the area (Pegram et al., 1981; NMSA, 2013).

\section{Conclusion}

The results of this study demonstrated that all cattle in the study sites and farms were infested by ticks of Subgenus Boophilus, Amblyomma, Hyalomma and Rhipicephalus tick genera. In addition, the number of ticks found on the animals from all breeds of cattle was found to be relatively small. Therefore the result clearly showed that all animals are found in endemic environment in which the burden do not cause economic loses mainly by reducing milk and 
meat yields, body weight gain, and risk of tick borne diseases. In addition, direct effect of ticks through skin and hide damage which downgrades quality and responsible for rejection of the product from national and international markets is also minimal. Therefore, tick infestation in the farms in the present epidemiological situation warrant strategic tick control in all study farms. In order to ascertain the current findings further studies such as prevalence of ticks to the species level and seasonal dynamics and biology of major economically important tick species should be conducted in the study areas. Only when we have these data it is possible to formulate the type of tick control methods in the present study areas and elsewhere.

\section{Acknowledgements}

We extend our appreciation to technical staff members of the College of Veterinary Medicine, Haramaya University for their assistance while collecting the ticks on the farms as well as when examining them in the laboratory.

\section{References}

Ambrose, N., Lloyd, D. and Maillard, J. C., 1999. Immune response to Dermatophilus congolensis infections. Parasitol. Today., 15, 295-300.

Birhanu T. and Abdalla, S., 2014. Prevalence and distribution of tick infestation on cattle at Fitche Selale, North Shewa, Ethiopia. LRRD. 26, 147. Retrieved March 23, 2016, from http://www.lrrd.org//rrd26/8/tade26147.htm

De Castro, J., 1997. Sustainable ticks and tick-borne disease control in livestock improvement in developing countries. Vet. Parasitol., 71, 69-76.

Fantahun, B., and Mohamed, A., 2012. Survey on the Distribution of Tick Species in and Around Assosa Town, Ethiopia. Res, J. Vet. Sci., 5, 32-41.

Furlong, J., Martins, J. R. and Prata, M. C. A., 2007. The tick of cattle and resistance: we have to celebrate. A Hora Vet. J., 27, 27-34.

Gebre S., . and Kaaya G., 1998. Development reproductive capacity and survival of Amblyomma variegartum and Boophilus decoloratus in relation host resistance and climatic factors under different field conditions. Vet. Prasitolo., 75, 241-253.

Getachew A., Mersha C., Dessalegne M. and Basaznew B., 2014. Prevalence of Ixodid Ticks on Cattle in Northwest Ethiopia. Acta Parasitol. Globalis, 5 (2), 139-145.

Ethiop. Vet. J., 2017, 21 (1), 16-28 
Hezron, N. E., Adrian, M. and Robinson, M., 2012. Tick infestations in extensively grazed cattle and efficacy trial of high-cis cypermethrin pour-on preparation for control of ticks in Mvomero district in Tanzania. BMC Vet. Res., 8, 224.

Hiko, A. and Wondimu, A., 2011. Occurrence of nematodiasis in Holstein Friesian dairy breed. J. Vet. Med. Anim. Hlth., 3 (1), 6-10.

Jongejan, F. and Uilenberg, G. 2004. The global importance of ticks. Parasitol., 129, 314.

Lodos, J., Boue, O. and Fuente, J., 2000. Model to simulate the effect of vaccination against Boophilus ticks on cattle. Vet. Parasitol., 87 (4), 315-326.

Lynen, G., Zeman, P., Bakuname, C., Giulio, G. D., Mtui, P., Sanka, P. and Jongejan, F., 2007. Cattle ticks of the genera Rhipicephalus and Amblyomma of economic importance in Tanzania: distribution assessed with GIS based on an extensive field survey. Exp Appl. Acarol., 43, 303-319.

Lynen, G., Zeman, P., Bakuname, C., Giulio, G. D., Mtui, P., Sanka, P. and Jongejan, F., 2008. Shifts in the distributional ranges of boophilus ticks in Tanzania: evidence that a parapatric boundary between Boophilus microplus and B. decoloratus follows climate gradients. Exp Appl. Acarol., 44, 147-164.

Mattioli, R. C., Pandey, V. S., Murray, M. and Fitzpatrick, J. L., 2000. Immunogenetic influences on tick resistance in African cattle with particular reference to trypanotolerant N'Dama (Bos Taurus) and trypanosusceptible zebu (Bos indicus) cattle. Acta Trop., 75, 263-277.

McCosker, P. J., Musisi, F. K., Lawrence, J. A., Quiroga, J. C., Kamwendo, S. P., 1993. The FAO multi-donor programme for integrated tick and tick-borne disease control in east, central and southern Africa, Proceeding of Tanzania veterinary association scientific conference, December 1993 Arusha. 11 $1^{\text {th }}$ Edn. Pp. 340-371.

Mekonnen S., 1996. Epidemiology of ticks and tick-borne diseases in Ethiopia: Future research needs and priorities. In: Irvin, A. D., McDermott, J. J. and Perry, B. D. (Eds.), Epidemiology of Ticks and Tick-borne Diseases in Eastern, Central and Southern Africa. Proceedings of a Workshop Held in Harare, 12-13 March 1996. ILRI (International Livestock in Research Institute), Nairobi, Kenya.

Mekonnen S., Hussein I. and Bedane, B., 2001. The distribution of ixodid ticks (Acari: Ixodidae) in central Ethiopia. Onderstepoort J. Vet. Res., 68, 243-251.

Morel, P., 1980. Tick distribution and vegetation zones in Ethiopia. Study on Ethiopian ticks (Acaridae, Ixodida), Pp. 259-266.

Musa, H. I., Jajere, S. M., Adamu, N. B., Atsanda, N. N., Lawal, J. R., Adamu, S. G. and Lawal, E. K., 2014. Prevalence of tick infestation in different breeds of cattle in Maiduguri, Northeastern Nigeria. Bangl. J. Vet. Med., 12 (2), 161-166. 
Nicholson, M. and Butterworth, T. 1996. A guide to body condition score in zebu cattle international livestock center for Africa, Addis Ababa, Ethiopia.

NMSA, 2013. National Metrology Service Agency (NMSA). Addis Ababa, Ethiopia, 2013. Ethiopia [Unpublished].

Ogden, N. H., Swai, E., Beauchamp, G., Karimuribo, E., Fitzpatrick, J. L., Bryant, M. J., Kambarage, D. M. and French, N. P., 2005. Risk factors for tick attachment to smallholder dairy cattle in Tanzania. Prev. Vet. Med., 67, 157-170.

Pegram, R. G. and Oosterwijk, G. P., 1990. The effect of Amblyomma variegatum on live weight gain of cattle in Zambia. Med. Vet. Entomol., 4, 327- 330.

Pegram, R., Hogstral, H. and Wassef H., 1981. Ticks (Acari: Ixodoidea) of Ethiopia. I. Distribution, ecology and host relationship of species infesting the livestock. Bull. Entomol. Res., 71, 339-359.

Regassa, F, 2001. Tick infestation of Borane cattle in the Borane Province of Ethiopia. Onderstepoort J. Vet. Res., 68, 41- 45.

Sajid, M. S., Iqbal, Z., Khan, M. N., Muhammad, G. and Iqbal, M.U., 2007. Effect of Hyalomma ticks (acari: ixodidae) on milk production of dairy buffaloes (Bos bubalus bubalis) of Punjab (Pakistan). Italian J. Anim. Sci., 6, 939-941.

Tessema, T. and Gashaw, A., 2010. Prevalence of ticks on local and crossbred cattle in and around Asella town, southeast Ethiopia. Ethiop. Vet. J.,14(2), 79-89.

Thrusfield, M. 2007. Veterinary Epidemiology. U.K. Black well science Ltd. Pp. 182198.

Tiki, B. and Addis, M., 2011. Distribution of Ixodid Ticks on Cattle in and Around Holeta Town, Ethiopia. Global Vet., 7 (6), 527-531.

Walker, R., Butiur, A., Estrada-pen, S., Hora, A., Latif, G., Pergam, A. and Preston, P. 2003. Tick of domestic animal in Africa, Guide to Identification Tick Species, Pp. 3-210.

Wasihun P. and Doda D., 2013. Study on prevalence and identification of ticks in Humbo district, Southern Nations, Nationalities, and People's Region (SNNPR), Ethiopia. J. Vet. Med. Anim. Hlth., 5(3), 73-80. 